\title{
First report of congenital or infantile cataract in deranged proteoglycan metabolism with released xylose
}

\author{
K N Sulochana, S Ramakrishnan, S B Vasanthi, H N Madhavan, K Arunagiri, R Punitham
}

Medical and Vision Research Foundations, Madras, India Department of Biochemistry K N Sulochana S Ramakrishnan K Arunagiri R Punitham

Department of Laboratory Services $S$ B Vasanthi

Microbiology Research Centre

H N Madhavan

Correspondence to: S Ramakrishnan,

Department of Biochemistry, Vision Research Foundation, 18 College Road, Madras 600006 , India.

Accepted for publication 13 January 1997

\begin{abstract}
Aim-To investigate the chemical pathology in the blood and lens, in cases of congenital or infantile cataract in children excreting predominantly non-reducing carbohydrates in urine.

Methods-Urine samples from children with congenital or infantile cataract, and age and sex-matched controls, were analysed for (i) inherited errors of metabolism, (ii) paper chromatography of sugars, (iii) spectrophotometric assay of glycosaminoglycans (GAG), (iv) cetyl trimethyl ammonium bromide test, (v) electrophoresis using Alcian blue, (vi) ion exchange chromatography with IR 120 resin, and (vii) HPLC for xylose. Blood and lens material were also tested for GAG fragments and xylose. $\beta$ Glucuronidase was assayed in lymphocytes and urine.
\end{abstract}

Results-Of 220 children of both sexes below 12 years of age, with congenital or infantile cataract treated in Sankara Nethralaya, Madras, India, during a period of 2 years, 145 excreted fragments of GAG (heparan and chondroitin sulphates) in their urine. There was no such excretion among the control group of 50 children. The same was found accumulated in the blood and lenses of affected children. In addition, xylose was present in small amounts in the urine and blood and xylitol was present in the lens. There was a significant elevation in the activity of $\beta$ glucuronidase in lymphocytes and urine, when compared with normals. All the above findings suggest deranged proteoglycan metabolism. As the urine contained mostly GAG fragments and very little xylose, Benedict's reagent was not reduced. This ruled out galactosaemia.

Conclusion-An increase of $\beta$ glucuronidase activity might have caused extensive fragmentation of GAG with resultant accumulation in the blood and lens and excretion in urine. Small amounts of xylose may have come from xylose links between GAG and core protein of proteoglycans. Owing to their polyanionic nature, GAG fragments in the lens might abstract sodium, and with it water, thereby increasing the hydration of the lens. Excessive hydration and the osmotic effect of xylitol from xylose might cause cataract. While corneal clouding has been reported in inborn acid mucopolysaccharidosis, congenital or infantile cataract with deranged metabolism of proteoglycans (acid mucopolysaccharide-xyloseprotein complex) is reported in children for the first time.

(Br f Ophthalmol 1997;81:319-323)

Congenital or infantile cataract is associated with inborn metabolic anomalies such as galactosaemia, ${ }^{1-4}$ and mannosidosis. ${ }^{5}$ Galactosaemia due to galactose-1-phosphate uridyl transferase $(\mathrm{EC}: 2.7 .7 .12)^{1}$ or galactokinase (EC: 2.7.1.6) ${ }^{346}$ deficiency has been well documented by many workers. The association of glycosaminoglycan (GAG) fragments or xylose, a pentose sugar, with congenital cataract, has not been reported hitherto. This study establishes the association of GAG fragments and xylose and congenital or infantile cataract.

Proteoglycans are essential components of the extracellular matrix of connective tissues (cartilage, tendon, and bone). They are polyanionic substances of high molecular weight and contain many different types of heteropolysaccharide repeating units covalently linked to a polypeptide chain backbone. The polysaccharide groups of the proteoglycans were formerly named mucopolysaccharides but the name glycosaminoglycan (GAG) is now preferred since all contain derivatives of either glucosamine or galactosamine. Six major classes of GAG are now known: hyaluronic acid, chondroitin-4-sulphate (CSA), chondroitin-6-sulphate (CSC), dermatan sulphate (CSB), keratan sulphate, and heparan sulphate (HS).

Small amounts of sugar (xylose), other than those constituting the amino and uronic acid repeating units of sugars, are found in some proteoglycans like CS and HS; they are located in the linkage regions joining the polysaccharide chains to the peptide moiety of the core protein. Degradation of the polysaccharide chains is carried out by hyaluronidase and $\beta$ glucuronidase. Hyaluronidase acts on hyaluronic acid and chondroitin sulphate to generate tetrasaccharides. $\beta$ Glucuronidase undertakes further catabolism of the tetrasaccharides. In addition to tetrasaccharides, its substrates include dermatan sulphate, heparan sulphate, chondroitin sulphate, and hyaluronic acid. In cases of inherited $\beta$ glucuronidase deficiency in humans, dermatan sulphate, heparan sulphate, and chondroitin sulphate compounds are excreted in the urine. 


\section{Materials and methods}

PATIENTS

The inclusion criteria were as follows: (i) children with bilateral, total soft cataract; (ii) cataract that is congenital or developmental; (iii) age group of birth to 12 years; (iv) both sexes taken; (v) children without galactosaemia; (vi) screening tests for rubella, cytomegalovirus, toxoplasma, Treponema pallidum, and herpes simplex virus (HSV) to be negative.

The exclusion criteria were: (i) cases with known or suspected cause for cataract, such as trauma or drugs; (ii) cases with congenital eye problems such as homocystinuria, gyrate atrophy, and Marfan's syndrome.

The controls were both physically and ophthalmically normal. They were the children of the staff of Sankara Nethralaya. In the test group, the urine and blood samples were analysed in the fasting condition well in advance of surgery (at least 1 week before). The lens aspirates were collected at the time of lensectomy. In test and control groups blood and urine samples were collected in the fasting condition. The study protocol had been approved by the research cell committee of the Vision Research Foundation and a research subcommittee of external experts.

Xylose, chondroitin sulphate, heparan sulphate, glucose, galactose, and other fine chemicals for standards were from Sigma Chemical Company, USA. All other chemicals and solvents used were of the analytical grade.

TESTS FOR INBORN ERRORS OF METABOLISM

The fresh urine samples were centrifuged and analysed for inborn errors of metabolism as follows: dinitrophenylhydrazine test for alpha keto acids; cyanide nitroprusside test for homocystine and cystine; ferric chloride test for phenyl pyruvic acid; Millon's test for tyrosine,${ }^{7}$ Molisch test for carbohydrates, ${ }^{8}$ and Benedict's test for reducing sugar. Urine samples were also tested for bilirubin and proteins to rule out liver or kidney dysfunction.

PAPER CHROMATOGRAPHY

This was performed using Whatman No 1 filter paper and n-butanol:acetic acid:water, as mobile phase in the ratio of $4: 1: 1$. The paper, after an overnight run, was dried in air and stained with aniline hydrogen oxalate $(0.9 \mathrm{ml}$ distilled aniline in $100 \mathrm{mM}$ oxalic acid). The stained paper was kept in a hot air oven at $90^{\circ} \mathrm{C}$ for 15 minutes. A pink spot with the same $R_{\mathrm{f}}$ as standard xylose showed the presence of xylose. ${ }^{9}$

ESTIMATION OF GAG BY SPECTROPHOTOMETRY This was done using the method of Gold ${ }^{10}$ with microgram quantities of GAG, following the formation of soluble complexes with Alcian blue dye. The method is based on the different absorption spectra of the dye and the dyeGAG complex. Samples of $0.1 \mathrm{ml}$ were mixed with $1.2 \mathrm{ml}$ of freshly prepared Alcian blue dye solution $(1.4 \mathrm{mg} / \mathrm{ml}$ in $0.5 \mathrm{M}$ sodium acetate) and absorbance at $480 \mathrm{~nm}$ was measured. A standard curve using 5-60 $\mu \mathrm{g}$ chondroitin sulphate was used for quantitation.
CETYL TRIMETHYL AMMONIUM BROMIDE TEST Five $\mathrm{ml}$ of fresh urine was added to $1 \mathrm{ml}$ of cetyl trimethyl ammonium bromide (cetavilon) solution $(50 \mathrm{~g} / 1$ in citrate buffer $(1 \mathrm{M})$ of $\mathrm{pH}$ 6.0 ). A heavy precipitate indicated the presence of mucopolysaccharides. ${ }^{11}$ Although 47 children in the control group excreted urine with a negative Molisch test, it was still considered desirable to find out if there was abnormal proteoglycan metabolism, as low levels of GAG may not be detected by the Molisch test. Therefore, 50 controls were also studied along with the children in the test group.

\section{ELECTROPHORESIS OF GAG FRAGMENTS}

Urine samples were centrifuged and 25-50 $\mu \mathrm{l}$ of the clear supernatant was applied on the wedge of the strip over an area of $1 \mathrm{~cm}$. Electrophoresis was performed for 1 hour at 10 $\mathrm{V} / \mathrm{cm}$ with $0.15 \mathrm{M}$ zinc acetate as buffer. After electrophoresis, strips were stained with $0.25 \%$ Alcian blue in methanol, acetic acid, water (50:5:45), and 5\% acetic acid was used for destaining. Standard chondroitin sulphate and heparan sulphate $2.5 \mu \mathrm{g}$ each in $25 \mu \mathrm{l}$ were also subjected to electrophoresis in a similar way. ${ }^{12}$

COLUMN CHROMATOGRAPHY USING AMBERLITE IR 120 CATION EXCHANGE RESIN

A glass column of $10 \times 2$ inches was packed with Amberlite resin IR 120, and washed and equilibrated with deionised water. Five $\mathrm{ml}$ of centrifuged clear urine was slowly passed through the resin. Three $\mathrm{ml}$ fractions were collected and analysed by paper chromatography for the presence of GAG and free xylose. One of the fractions showed only one pink spot with $\mathrm{R}_{\mathrm{f}}$ corresponding to standard xylose in chromatography. This fraction was further analysed by Bial's orcinol test specific for pentoses. For this, an aliquot of the same fraction was treated with orcinol reagent $(0.3 \%$ in $\mathrm{HCl})$ in the presence of ferric chloride. It gave a green colour showing the presence of pentose which was identified as xylose by high performance liquid chromatography (HPLC).

\section{HPLC ANALYSIS}

LKB superpack cartridge $4.0 \times 250 \mathrm{~nm}$, Spherisorb ODS2.5 $\mu \mathrm{m}$. Octadecyl silane column with HPLC grade distilled water as mobile phase was used with a flow rate of 1 $\mathrm{ml} / \mathrm{min}$ and detection at $188 \mathrm{~nm}$, UV $0.02 \mathrm{AUFS} .{ }^{13} \mathrm{~A}$ volume of $250 \mu \mathrm{l}$ of the fraction from column chromatography which was positive to Bial's orcinol test was injected through the column. It was eluted in 9 minutes. Standard xylose (Sigma) also had the same retention time.

\section{PREPARATION OF ENZYME EXTRACT}

Lymphocytes were collected from $5 \mathrm{ml}$ heparinised blood by the method of Berger ${ }^{14}$ and grown for 72 hours in minimum essential medium supplemented with $10 \%$ fetal calf serum and phytohaemagglutinin. Harvested cells were sonicated at 60 kilocycles for $30 \mathrm{sec}-$ onds to extract the enzyme. 
Table 1 Screening test for mucopolysaccharides; cetyl trimethyl ammonium bromide test in urine of children with congenital or infantile cataract

\begin{tabular}{lcc}
\hline Result & Frequency & Percentage \\
\hline Nil & 3 & 2.1 \\
Mild & 23 & 15.86 \\
Moderate & 81 & 55.9 \\
Severe & 38 & 26.2 \\
Total & 145 & 100
\end{tabular}

Appearance of heavy precipitate indicates the presence of mucopolysaccharides in the sample. The amount of precipitate depends on the concentration of mucopolysaccharides. Depending upon their concentration, samples were classified as negative, mild, moderate, and severe. Only two children from the control group had mild reaction, while samples from the rest did not show any precipitate.

\section{ENZYME ASSAY}

This assay is a modification of the method of Kawai and Anno. ${ }^{15}$ The reaction mixture was $0.4 \mu \mathrm{M} p$-nitrophenyl- $\beta$-D-glucuronide and enzyme in acetate buffer at $\mathrm{pH} 4.5$, incubated at $37^{\circ} \mathrm{C}$ for 1 hour. At the end of this period, the enzyme reaction was arrested with the addition of glycine buffer ( $\mathrm{pH}$ 10.7). The amount of $p$-nitrophenol liberated was determined using the Beckman DU 640 spectrophotometer at $400 \mathrm{~nm}$. The protein content in the enzyme extract was determined by the method of Lowry et al. ${ }^{16}$ The enzyme activity was expressed as $\mathrm{nM}$ of nitrophenol liberated/mg protein.

\section{B GLUCURONIDASE ESTIMATION IN URINE}

A random sample was collected in a sterile container and enzyme activity was performed as given above for lymphocytes with urine in place of enzyme extract. Creatinine content of the urine was determined by the method of Bonsnes and Taussky. ${ }^{17}$ The enzyme activity was expressed in terms of $\mathrm{nM}$ of nitrophenol liberated/mg of creatinine excreted in urine.

\section{Results}

Two hundred and twenty children with congenital or infantile cataract and 50 controls were studied for inborn errors of metabolism over a period of 2 years. One hundred and forty eight children from the cataract group, and three controls showed a positive reaction to the Molisch test. The three children who showed positive Molisch reactions from the control group also showed positive Benedict's tests. They had lactose in their urine. This was confirmed by paper chromatography. None of them had galactose, xylose, or GAG fragments.

Among the 148 children with cataract showing positive Molisch tests in urine, eight were also Benedict's positive. In this group of eight, three were galactosaemic and five showed the presence of lactose along with GAG fragments. All the 145 cases (Table 1) were subjected to further investigations.

The results of spectrophotometric determination of total GAG are given in Table 2. A significant number (84) of cases showed elevated levels $(101-500 \mu \mathrm{g} / \mathrm{ml})$ of $\mathrm{GAG}$ in their urine. A typical paper chromatogram of the urine of children with cataract, studied for carbohydrates, is shown in Figure 1. Along with GAG fragments, they also had free xylose
Table 2 Spectrophotometric estimation of total glycosaminoglycans (GAG) in urine of children with congenital or infantile cataract

\begin{tabular}{lcc}
\hline Levels of $G A G(\mu \mathrm{g} / \mathrm{ml})$ & Frequency & Percentage \\
\hline Not detectable & 12 & 8.3 \\
$25-100$ & 39 & 26.9 \\
$101-500$ & 84 & 57.9 \\
$501-1000$ & 6 & 4.1 \\
$>1000$ & 4 & 2.7 \\
Total & 145 & 100 \\
\hline
\end{tabular}

In the control group 23 children had $25-100 \mu \mathrm{g} / \mathrm{ml}, 2$ children $120 \mu \mathrm{g} / \mathrm{ml}$, and rest below the detectable level.

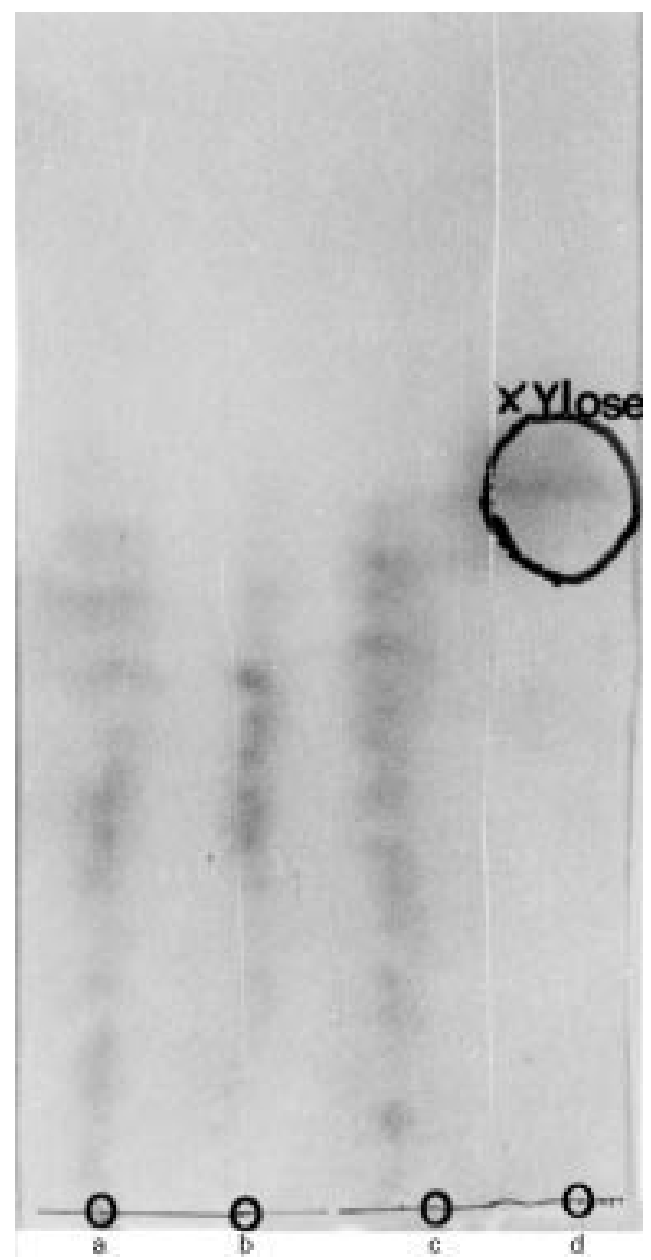

Figure 1 Paper chromatogram showing the presence of $x y$ lose and glycosaminoglycan fragments in urine samples of children with congenital cataract. $(a, b, c)$ are three

different representative cases of congenital cataract, and (d) is standard xylose.

in urine. In eight of 145 chromatographically detected xylose positive cases, the quantity of xylose was high enough to give a positive Benedict's test. Serum samples showed brown spots in a staircase-like fashion. Although the lens homogenate of these children showed GAG fragments in a significant number of cases, the xylose spot was not prominent. However, when chromatography was performed after oxidation of the lens homogenate with dilute potassium permanganate, the xylose spot was clearly identified (Fig 2).

A typical electropherogram of GAG is shown in Figure 3. A highly significant number-that is, $80 \%$ of Molisch positive cases, showed the presence of two arcs, one in 


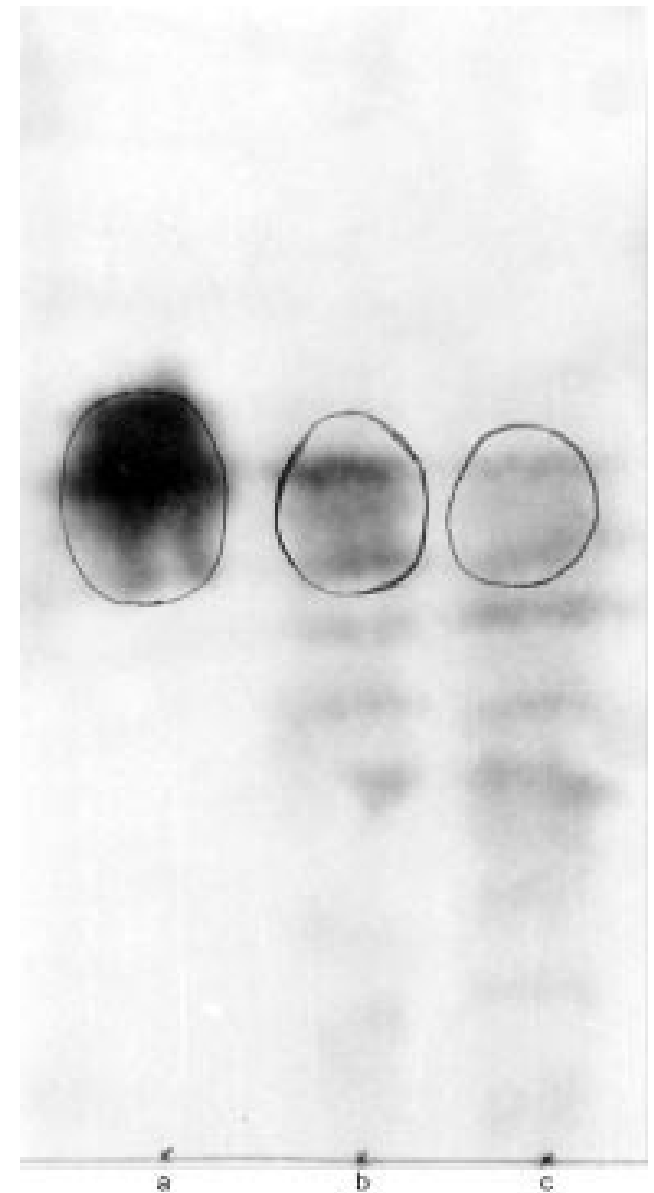

Figure 2 Paper chromatogram showing the presence of xylose from xylitol in the lens aspirate of children with congenital cataract. (a) Standard xylose, (b) lens aspirate of child with congenital cataract after oxidising with potassium permanganate, (c) serum sample of a child with congenital cataract.

the CS region and the other in that of heparan sulphate. All the 50 urine samples from the control group were also subjected to electrophoresis and none showed any arcs for heteropolysaccharides.

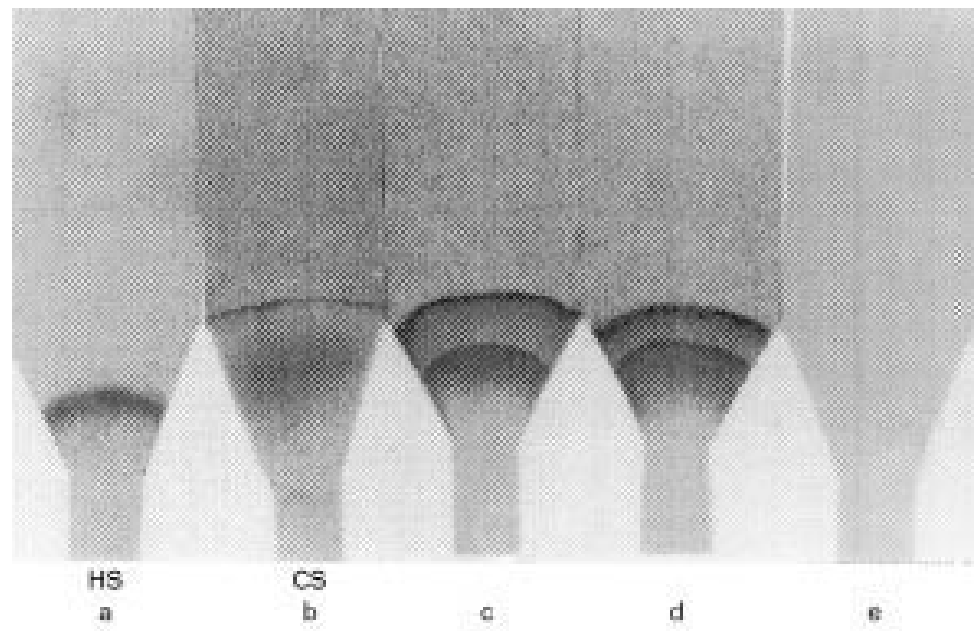

Figure 3 Electrophoretic profile of standard $G A G$, urine sample of normal and congenital cataract children. (a) Standard GAG (HS, heparan sulphate), (b) standard GAG (CS, chondroitin sulphate), (c) and (d) two representative urine samples of children with congenital cataract showing the presence of GAG fragments, (e) normal urine, did not show any $G A G$ fragments.

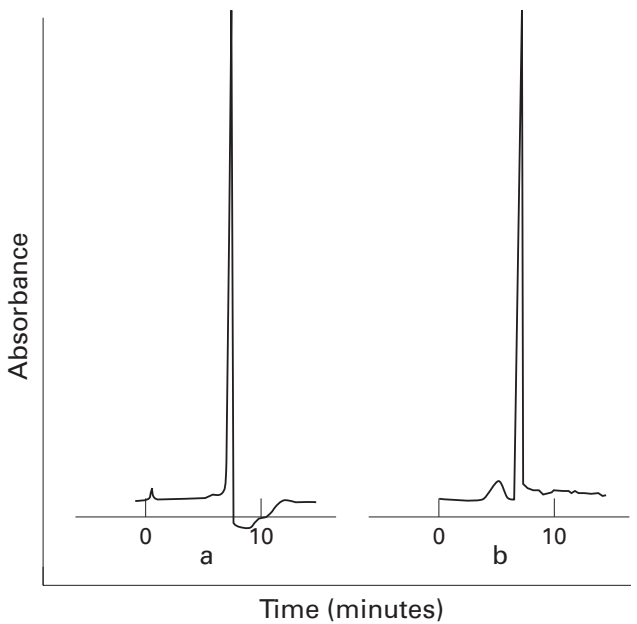

Figure 4 HPLC elution profile. (a) Standard xylose, (b) the ion exchange chromatography fraction, which showed a single pink spot on paper chromatography when stained for sugar. Both sample and standard showed a similar peak with a retention time of 9.0 minutes.

In ion exchange chromatography, the elution was followed by the analysis of the fractions for sugars. One of the fractions showed only one pink spot in paper chromatography and this fraction was positive to Bial's orcinol test, confirming the presence of pentose. It was also subjected to HPLC. Conditions were maintained as given in the methods section. Standard xylose was also treated in the same way. The retention time for both the standard and the test was the same- - that is, 9 minutes (Fig $4)$.

The median $\beta$ glucuronidase activities in the lymphocytes (Table 3 ) were as follows: affected children below 3 years, 40; above 3 years and below 12 years, 50; in controls below 3 years, 6 ; above 3 years and below 12 years, 7; in urine (Table 4) of children below 3 years with cataract, 30; and above 3 years and below 12 years, 22.5; in controls below 3 years, 9; and above 3 years and below 12 years, 13. The Mann-Whitney-Wilcoxon rank sum test was applied for statistical analysis. Results are significant as given by $\mathrm{p}$ values.

\section{Discussion}

Acid mucopolysaccharidosis is associated with bone deformities, mental retardation, facial dysmorphism, and hepatosplenomegaly. Some of the patients were reported to have corneal clouding but not cataract. One case of mucopolysaccharidosis type I referred to us by the paediatrics department of Child Trust Hospital, Madras, had bone changes, excretion of GAG fragments in urine and a definite lens opacity with anterior subcapsular cataract. It was a case of infantile cataract. Congenital cataract has been associated with Marfan's syndrome excreting GAG. Our test group of children did not have Marfan's syndrome, since they did not excrete hydroxyproline, an amino acid unique for collagen diseases, and did not have the other ocular manifestations such as ectopia lentis which is reported in patients with Marfan's syndrome. ${ }^{18}$

Hyaluronidase acts on hyaluronic acid, heparan sulphate, and chondroitin sulphate to 
Table $3 \beta$ Glucuronidase activity in lymphocytes, $n M$ of nitrophenol liberated/mg protein (cataract $v$ non-cataract)

\begin{tabular}{lllcll}
\hline Age group & Category & $N$ & Median & Range & p Value $^{\star}$ \\
\hline Below 3 years & Cataract & 6 & 40.0 & $(30,70)$ & \\
& Non-cataract & 5 & 6.0 & $(4,8)$ & 0.006 \\
Above 3 years and below 12 & Cataract & 4 & 50.0 & $(40,80)$ & \multirow{2}{*}{0.014} \\
years & Non-cataract & 5 & 7.0 & $(5,10)$ & 0.014 \\
\hline
\end{tabular}

^By Mann-Whitney-Wilcoxon rank sum test.

Table $4 \quad \beta$ Glucuronidase activity in urine, $n M$ of nitrophenol liberated/mg creatinine (cataract $v$ non-cataract)

\begin{tabular}{llllll}
\hline Age group & Category & $N$ & Median & Range & p Value \\
\hline Below 3 years & Cataract & 6 & 30.0 & $(20,40)$ & \multirow{2}{*}{ Non-cataract } \\
Above 3 years and below & 5 & 9.0 & $(7,15)$ & 0.006 \\
12 years & Cataract & 4 & 22.5 & $(10,60)$ & \multirow{2}{*}{0.327} \\
\hline
\end{tabular}

^By Mann-Whitney-Wilcoxon rank sum test.

generate tetrasaccharides. These tetrasaccharides are further degraded by $\beta$ glucuronidase, an exoglycosidase that hydrolytically removes glucuronic acid from tetrasaccharides ${ }^{19}$ and is localised in lysosomes and microsomes. Its substrates include tetramers of dermatan sulphate, heparan sulphate, chondroitin sulphate, and hyaluronic acid and the respective heteropolysaccharides. In inherited $\beta$ glucuronidase deficiency dermatan sulphate, heparan sulphate, and chondroitin sulphate degradation products are excreted in the urine. The electrophoretic pattern had shown the presence of the fragments of CS and HS but not of hyaluronic acid. Only these polysaccharides have xylose attached to the serine of the core protein of proteoglycan. So, the excretion of these fragments and xylose in urine suggested deficiency of $\beta$ glucuronidase in these children. However, contrary to our expectation, our results showed a significant elevation of the enzyme activity. Therefore it appears that heteropolysaccharides might be extensively hydrolysed by $\beta$ glucuronidase to release their fragments in blood and urine. In the absence of any possible microbial infection, the elevated levels of $\beta$ glucuronidase activity could not be explained other than by genetic error. Molecular screening for genetic mutation of the DNA coding for this enzyme can give some insight into this problem.

An elevation of enzyme activity in an inborn error of metabolism is rare and hence the observed increase of $\beta$ glucuronidase may be secondary to the real abnormality in this series of children.

Owing to their relatively small molecular weight and anionic nature, GAG fragments might enter the lens and abstract $\mathrm{Na}^{+}$ions and also water, causing opacity of the lens as a result of excessive hydration. Xylose found to be present in the lens as xylitol, might also contribute to cataractogenesis. Xylose feeding of animals has been reported to cause cataract in a similar way as galactitol from galactose in galactosaemia. $^{20}$
The molecular mechanism in congenital or infantile cataract with impaired proteoglycan metabolism thus appears to be due to accumulation of both xylitol from xylose and GAG fragments in the lens.

While 145 of 220 children had congenital or infantile cataract with association of abnormal proteoglycan metabolism, only three had galactosuria. Lactose excreted in urine by normal children can be physiological, as some children are reported to be lactosuric. ${ }^{9}$

The study offers valuable genetic counselling. If affected by galactosaemic cataract, children should avoid milk and milk products, since galactose from lactose accumulating in their blood will cause cirrhosis of liver, pancreatitis, etc, but the children with congenital cataract due to GAG fragments and xylose can take milk without restriction. Thus, this finding has implications in community ophthalmology with a valuable message for the public.

1 Kalckar HM, Anderson EP, Isselbacher KJ. Galactosemia, a congenital defect in a nucleotide transferase. Biochem Biophys Acta 1956;20:262-6.

2 Gitzelman R. Hereditary galactokinase deficiency, a newly recognized cause of juvenile cataract. Pediatr Res 1967;1: $14-16$.

3 Levy NS, Krill AE, Beutler E. Galactokinase deficiency and cataract. Am f Ophthalmol 1972;74:41-9.

4 Kinoshita JH. Cataracts in galactosemia. Invest Ophthalmol Vis Sci 1965;4:786-92.

5 Aguirre G, Stramm L, Haskin M, Jezyk P. Animal models of metabolic eye diseases. In: William AR, ed. Goldberg's genetic and metabolic eye disease. 2nd ed. USA, 1986:129-67.

6 Murphree AL. Cataracts in galactosemia. Invest Ophthalmol Vis Sci 1965;4:786-92.

7 Gowenlock AH, Murray JR, McLavchlan, DM. Specific methods for detection of amino acids and their derivatives. In: Varley H, Gowenlock AH, Bell M, eds. Varley's practical clinical biochemistry. 6th ed. London: William Heinemann, 1988:383-98.

8 Rajagopal G, Ramakrishnan S. Qualitative analysis of carbohydrates. In: Practical biochemistry for medical students. carbohydrates. In: Practical bioc

9 Varley $\mathrm{H}$, Gowenlock AH, Bell M. Tests for glucose and other reducing substances in urine. General topics and commoner tests. In: Varley H, Gowenlock AH, Bell M, eds. Practical clinical biochemistry, Vol I 5th ed. London:William Heinemann, 1980:421-35.

10 Gold EW. A simple spectrophotometric method for estimating glycosaminoglycan concentrations. Anal Biochem 1979; 99:183-8.

11 Varley H, Gowenlock AH, Bell M. Screening procedures for inherited disorders. In: Varley H, Gowenlock AH, Bell M, eds. Practical clinical biochemistry. Vol 1. London: William Heinemann, 1990:523-4.

12 Rufini S, Ghebregzabher M, Castellucci G, Lato M. A new screening test for the diagnosis of mucopolysaccharidoses. Clin Chem Acta 1979;95:443-4.

13 Binder H. Separation of monosaccharides by HPLC comparison of ultraviolet and refractive index detection. $\mathcal{F}$ Chromatogr 1980;189:414-20.

14 Berger SL. Lymphocytes as resting cells. Methods in Enzymol 1979;58:486-9

15 Kawai Y, Anno KL. Mucopolysaccharide-degrading enzymes from the liver of the squid, Ommastrepars sloanipacificus. Biochem Biophys Acta 1971;242:428-38.

16 Lowry OH, Rosebrough NJ, Farr AL, Randall RJ. Protein measurement with Folin phenol reagent. F Biol Chem 1951; 193:265-75.

17 Bonsnes RW, Taussky HH. Non-protein nitrogen. In: Varley H, Gowenlock AH, Bell M, eds. Practical clinical biochemistry. Vol 1, 5th ed. London: William Heinemann, 1980:484.

18 Prockop DJ, Sjoerdsma A. Significance of urinary hydroxy proline in man. F Clin Invest 1961;40:843-6.

19 Murray RK, Granner DK, Mayes PA, Rodwell VW. GlycoMurray RK, Granner DK, Mayes PA, Rodwell
proteins and proteolglycans. In: Harper's biochemistry. 21 st proteins and proteolglycans. In: Harper's biochemistry.

20 Yeh LA, Rafford CE, Beyer TA, Hutson NJ. Effects of the aldose reductase inhibitor Sorbinil on the isolated cultured rat lens. Metabolism 1986;35:4-9. 